\title{
Molecular mechanisms underlying formation of long-term reward memories and extinction memories in the honeybee (Apis mellifera)
}

\author{
Dorothea Eisenhardt \\ Department of Biology, Chemistry, Pharmacy, Institute of Biology, Neurobiology, Freie Universität Berlin, 14195 Berlin, Germany
}

\begin{abstract}
The honeybee (Apis mellifera) has long served as an invertebrate model organism for reward learning and memory research. Its capacity for learning and memory formation is rooted in the ecological need to efficiently collect nectar and pollen during summer to ensure survival of the hive during winter. Foraging bees learn to associate a flower's characteristic features with a reward in a way that resembles olfactory appetitive classical conditioning, a learning paradigm that is used to study mechanisms underlying learning and memory formation in the honeybee. Due to a plethora of studies on appetitive classical conditioning and phenomena related to it, the honeybee is one of the best characterized invertebrate model organisms from a learning psychological point of view. Moreover, classical conditioning and associated behavioral phenomena are surprisingly similar in honeybees and vertebrates, suggesting a convergence of underlying neuronal processes, including the molecular mechanisms that contribute to them. Here I review current thinking on the molecular mechanisms underlying long-term memory (LTM) formation in honeybees following classical conditioning and extinction, demonstrating that an in-depth analysis of the molecular mechanisms of classical conditioning in honeybees might add to our understanding of associative learning in honeybees and vertebrates.
\end{abstract}

\section{Reward memories in honeybees}

The honeybee (Apis mellifera) has long served as an invertebrate model organism for reward learning and memory research (Menzel 2012). Its value as a model organism in this area is rooted in its impressive capacity for learning and memory formation. Honeybees are social insects that exhibit a prounounced divison of labor. During the summer season a honeybee colony consists of a single, reproductive queen, a few hundred drones, and tens of thousands of sterile worker bees. Depending on their age, worker bees either work inside the hive and fulfill hive duties such as brood rearing, or forage outside the hive collecting nectar or pollen to nourish the queen, workers, and brood. During the winter, long-living worker bees stay inside the hive, clustering around the queen to keep her temperature constant and ensure her survival. Survival during the winter season is only possible when sufficient nectar and pollen has been collected during the summer and is stored in the hive (Seeley and Visscher 1985; Winston 1991; Seeley 1995.

Honeybees visit one particular flower species during a foraging trip and collect nectar and pollen from the same food source as long as it is productive (Free 1963; Greggers and Menzel 1993; Greggers and Mauelshagen 1997; Gruter et al. 2011). Accordingly, honeybees learn the properties of a food source including its location and sensory characteristics such as odor, color, and shape (von Frisch 1967; for recent reviews, see Sandoz 2011; AvarguesWeber and Giurfa 2013; Hempel de Ibarra et al. 2014). They also learn the quantity or quality of the food source and the time of day at which it displays its highest total sugar concentration (Menzel 1968; Menzel and Erber 1972; Buchanan and Bitterman 1988, 1989; Lee and Bitterman 1990; Couvillon et al. 1991, 1994; Loo and Bitterman 1992; Couvillon and Bitterman 1993; Hoban et al. 1996; Moore 2001; Gil et al. 2007; Gil and De Marco 2009; Moore and Doherty 2009; Gil 2010; Edge et al. 2012).

\section{Corresponding author: dorothea.eisenhardt@fu-berlin.de} Article is online at http://www.learnmem.org/cgi/doi/10.1101//m.033118.113.

\section{Classical olfactory conditioning resembles associative learning during foraging}

Learning an association between the characteristic features of a food source and the reward of food resembles Pavlovian classical conditioning, in which an animal learns that a conditioned stimulus (CS) predicts the occurrence of a meaningful unconditioned stimulus (US). Accordingly, the mechanisms that underlie honeybee reward learning are studied in individual honeybees that have been classically conditioned according to an appetitive Pavlovian conditioning paradigm based on the olfactory conditioning of the proboscis extension response (PER) (Takeda 1961; Bitterman et al. 1983; Felsenberg et al. 2011; Giurfa and Sandoz 2012; Matsumoto et al. 2012). In this paradigm, honeybees learn the association between an initially neutral olfactory stimulus, the conditioned stimulus (CS), and a sucrose stimulus, the unconditioned stimulus (US). The presentation of the US alone elicits an unconditioned response (UR), i.e., the extension of the proboscis when the antennae or the proboscis of a honeybee come into contact with sucrose solution. This response is termed the proboscis extension response (PER). Once the association between the olfactory CS and the rewarding US has been learned, the CS alone elicits the PER. When a PER is elicited by the CS alone following classical conditioning, this response resembles the conditioned response (CR). Accordingly, during appetitive classical conditioning the $\mathrm{CS}$ is learned as the predictor of the rewarding US, acquiring excitatory properties that elicit the CR.

In experiments on PER conditioning in honeybees, a group of insects is conditioned each day and the conditioned response is

\footnotetext{
C 2014 Eisenhardt This article is distributed exclusively by Cold Spring Harbor Laboratory Press for the first 12 months after the full-issue publication date (see http://learnmem.cshlp.org/site/misc/terms.xhtml). After 12 months, it is available under a Creative Commons License (AttributionNonCommercial 4.0 International), as described at http://creativecommons. org/licenses/by-nc/4.0/.
} 
tested during memory retrieval. The PER to the presentation of the CS during conditioning and memory retrieval is recorded for each individual and the percentage of bees that respond with the PER is analyzed (Felsenberg et al. 2011; Matsumoto et al. 2012). A significant increase in the percentage of animals responding with a PER during conditioning is interpreted as learning. A high percentage of animals responding to the CS during memory retrieval is interpreted as an indication of the formation of a strong memory, whereas a low percentage of animals is interpreted as a weak memory. Accordingly, the group behavior of animals is seen as an indication of the probability that learning and memory formation will occur in an individual animal. However, Pamir et al. (2011) report a step-like, stable change of behavior of individual honeybees during classical conditioning that contrasts with the gradually increasing learning curve observed in group behavior: Once a bee responds to the CS during conditioning, the probability that this insect will again respond to the CS during conditioning and memory retrieval is higher than the probability that it will not respond. This step-like change in the behavioral response is most likely attributed to the dichotomous nature of the behavior recorded (proboscis extension: yes or no) and is not necessarily an indication that the underlying neuronal and molecular processes also proceed in a step-wise manner. This step-like behavior does, however, provide an opportunity to differentiate between the learning behavior of individual bees ("learners" vs. "nonlearners") and to examine the neuronal and molecular processes that underlie it (Matsumoto et al. 2012).

\section{Common principles underlying classical conditioning in honeybees and vertebrates}

Appetitive classical conditioning in the honeybee has been characterized with an impressive depth, making the honeybee one of the best-characterized invertebrate models from the point of view of psychological learning theory. Several learning phenomena known from studies on classical conditioning in vertebrates have been demonstrated in honeybees, including trace conditioning (Szyszka et al. 2011), backward conditioning (Bitterman et al. 1983; Hellstern et al. 1998; Dacher and Smith 2008; Felsenberg et al. 2014a), second-order conditioning (Hussaini et al. 2007), extinction learning (Sandoz and Pham-Delegue 2004; Stollhoff et al. 2005; Eisenhardt and Menzel 2007; Stollhoff and Eisenhardt 2009; Plath et al. 2012), sensory preconditioning (Müller et al. 2000), and blocking (Guerrieri et al. 2005; for a contrasting review, see Gerber and Ullrich 1999), latent inhibition (Chandra et al. 2010), and occasion setting (Mota et al. 2011). These phenomena are surprisingly similar to vertebrates, in which they were initially described (Bouton 1993; Fanselow 1998; Schmajuk et al. 1998; Myers and Davis 2002; Gewirtz and Davis 2006; Denniston and Miller 2007; Raybuck and Lattal 2014). This suggests that the underlying neuronal mechanisms are also likely based on common principles. A resemblance between behavioral performance does not necessarily imply a similar principle at every level of the nervous system and one should not expect, given gross differences between brain anatomy in honeybees and vertebrates, that similarities in classical conditioning are due to common overall brain organization. However, common principles might be found at the level of neuronal circuits and through connectivity within defined circuits, i.e., similar "connectomes," or similar types of neurons that "serve as a basis of a common vocabulary," and may be based on closely related molecular mechanisms (Bargmann and Marder 2013).

Indeed, several lines of evidence suggest that common principles might be found at the molecular level. The honeybee genome project revealed a plethora of honeybee proteins homologous to vertebrate neuronal proteins (Honeybee Genome Se- quencing Consortium 2006). In addition, converging work on the molecular mechanisms of synaptic plasticity in invertebrates and vertebrates suggests similar principles regarding the neuronal basis of learning and memory formation (Glanzman 2010). Furthermore, growing evidence in vertebrates suggest that the evolution of neuronal proteins has contributed to the evolution of complex learning behavior (Nithianantharajah et al. 2013; Ryan et al. 2013), suggesting that less complex forms of learning in invertebrates might be based on molecules and molecular mechanisms that are similar to those of vertebrates. Given the surprising similarities between honeybees and vertebrates with respect to classical conditioning and its related behavioral phenomena, I thus hypothesize that these molecular mechanisms might rest on a common principle that makes the honeybee a particularly interesting invertebrate model organism for learning and memory research. To illustrate this hypothesis, I will here review the molecular mechanisms that underlie the formation of long-term memories following classical conditioning and extinction in honeybees.

\section{Two long-term reward memories are distinguishable in honeybees}

The molecular mechanisms of honeybee appetitive Pavlovian conditioning and memory formation have been examined in depth over the last $20 \mathrm{yr}$. Depending on the time points of pharmacological interference and memory retrieval, molecular mechanisms that underlie the formation of short-term memory (STM), mid-term memory (MTM), early long-term memory (eLTM), and late long-term memory (ILTM) are distinguished (Menzel 1999, 2001; Müller 2002, 2013; Schwärzel and Müller 2006). Here, I will focus solely on the mechanisms of long-term memory formation since the mechanisms of coincidence detection, STM and MTM formation during and after classical conditioning have been reviewed and discussed elsewhere (e.g., Menzel 1999, 2001; Müller 2002, 2013; Eisenhardt 2006; Schwärzel and Müller 2006).

Long-term memories are particularly stable memories. Their formation depends on the synthesis of new proteins that contribute to structural changes and thus to the stability of specific memory traces. Accordingly, long-term memories undergo a stabilization process during which translation and transcription take place. This process is termed memory consolidation, and the subsequent long-term memories are therefore defined as consolidated memories (Dudai 2004).

Two different consolidated memories which form following classical conditioning with three CS-US pairings, i.e., conditioning trials, can be dissociated due to their differential sensitivity to translational and transcriptional inhibitors (for review, see Müller 2013). The formation of eLTM is sensitive to the translational inhibitor emetine (Friedrich et al. 2004; Stollhoff et al. 2005) but not to anisomycin (Wustenberg et al. 1998; Felsenberg et al. 2011), whereas ILTM depends on anisomycin-sensitive translation as well as actinomycin D-sensitive transcription and is visible $3 \mathrm{~d}$ after three-trial conditioning (Wustenberg et al. 1998; Friedrich et al. 2004; Felsenberg et al. 2011; Lefer et al. 2012; Matsumoto et al. 2014). It is noteworthy that these two different memories can be distinguished through the use of different inhibitors for translation (eLTM: emetine, ILTM: anisomycin). Why these two inhibitors of protein synthesis differentially target eLTM and ILTM is not yet understood. Their different modes of action could be one explanation for the sensitivity of different LTMs to these two protein synthesis inhibitors: Emetine binds the small ribosomal 40S subunit inhibiting aminoacyl tRNAs transfer but does not prevent the transpeptidation or translocation of peptidyl-tRNA from acceptor to donor sites (Grollman 1968; Gupta 
and Siminovitch 1977; Boersma et al. 1979; Rhoads and Roufa 1985; Wong et al. 2014). Anisomycin, on the other hand, binds to the large ribosomal 605 subunit, inhibiting its peptidyltransferase activity and thus the formation of peptide bonds (Hansen et al. 2003). Additionally, anisomycin not only inhibits translation, but seems to enhance the expression of immediate early genes, a process termed gene superinduction (for reviews, see Alberini 2008; Radulovic and Tronson 2008). Thus it is possible that anisomycin and emetine cause differences in LTM formation because of these additional effects of anisomycin.

Besides its sensitivity to anisomycin, a second unique feature of ILTM is its sensitivity to the transcriptional inhibitor actinomycin D (Grunbaum and Müller 1998; Wustenberg et al. 1998; Friedrich et al. 2004). Transcription has therefore been assumed to be the sole prerequisite for ILTM formation. Meanwhile, an involvement of epigenetic mechanisms in honeybee LTM formation has also been reported. Epigenetic processes such as histone acetylation, histone methylation, and DNA methylation regulate gene expression (Puckett and Lubin 2011). Merschbaecher et al. (2012) demonstrated that the acetylation of histones is crucial for eLTM formation. Acetylation by the histone acetyltransferase (HAT) results in chromatin opening, thereby permitting transcription, whereas histone deacetylation by histone deacetylases (HDACs) has a repressive effect on transcription (Cho and Cavalli 2014). In honeybees an enhancement of histone acetylation after classical conditioning is observed when comparing classically conditioned animals with animals that received an unpaired presentation of CS and US. In line with this, the inhibition of HAT inhibits eLTM formation, whereas HDAC enhances it (Merschbaecher et al. 2012). Moreover, the DNA methyltransferase 3 (dnmt3) gene is up-regulated $30 \mathrm{~min}$ after classical conditioning in honeybees (Lockett et al. 2010), and the ability of honeybees to differentiate between a learned odor and a novel odor at 1 and $3 \mathrm{~d}$ after conditioning is affected by the inhibition of DNA methylation (Biergans et al. 2012). This is particularly interesting because there are indications that $d n m t 3$ might regulate alternative splicing in honeybees (Li-Byarlay et al. 2013).

These results are in contrast to the notion that transcription is a process that mediates only ILTM formation. One reason for this contradiction could be the "qualitatively different effects" that epigenetic mechanisms and actinomycin D have on transcription (Merschbaecher et al. 2012). HADC and HAT, for example, regulate the binding of histones to DNA and hence also the degree of DNA condensation as a precondition for transcription of a specific set of genes. In contrast, actinomycin D intercalates in the DNA double helix, preferentially blocking transcription in so-called transcription bubbles that have already been unwound by DNA helicases (Sobell 1985; Puckett and Lubin 2011; Paramanathan et al. 2012). Clearly, the learning-dependent regulation of transcription is still poorly understood and must be clarified in future experiments in honeybees. However, the results of studies on epigenetic processes indicate that transcriptiondependent processes are not a unique feature of ILTM formation, but play a role in eLTM formation as well.

The fact that translation, transcription, and epigenetic processes are required for long-term memory formation suggests that de novo synthesized proteins are involved in this process in honeybees, although exactly which proteins are synthesized de novo after learning remains unclear. The antennal lobes (AL) and mushroom bodies (MB) are neuropiles of the honeybee brain where odor and reward pathways converge and thus where memory traces might be formed (Hammer and Menzel 1995). In both neuropiles, a structural reorganization is observed in areas of high synaptic density $3 \mathrm{~d}$ after conditioning (Hourcade et al. $2009,2010)$. In the MB this requires transcription and thus most likely indicates de novo protein synthesis (Hourcade et al.
2010). These studies suggest that at least some of the proteins synthesized de novo following classical conditioning are synaptic proteins. Indeed in mice, where an analysis of the proteome following associative learning has been performed, a quantitative increase was found in $23 \%$ of proteins of the synaptic proteome after associative learning (Kahne et al. 2012).

In the same study, quantitative decreases were observed in more than twice as many synaptic proteins (59\%) (Kahne et al. 2012). So not surprisingly, recent studies have demonstrated that protein degradation plays a role in long-term memory formation. In particular, the ubiquitin proteasome system (UPS) seems to be involved in LTM formation in invertebrate and vertebrate model organisms (for review, see Jarome and Helmstetter 2013). The UPS system is a network of ubiquitin ligases and proteasomal structures that label proteins for subsequent degradation by the proteasome (Sommer and Wolf 2014). In the honeybee, the proteasome inhibitors Z-Leu-Leu-Leu-CHO (MG132) and clasto-lactacystein $\beta$-lactone enhance eLTM and ILTM following conditioning with three CS-US trials (Felsenberg et al. 2012, $2014 b$ ). Accordingly, protein degradation in honeybees modulates LTM strength rather than being a prerequisite for LTM formation. This finding is in contrast to studies in other invertebrate and vertebrate model organisms, in which the inhibition of protein degradation with proteasome inhibitors during memory formation blocks LTM formation. Most of these experiments were performed in aversive learning paradigms. It remains to be shown whether this contradiction can be attributed to differences in LTM formation between honeybees and other model organisms or to differences in the mechanisms of appetitive and aversive LTM formation (Felsenberg et al. 2014b).

In summary, the formation of both eLTM and ILTM in honeybees depends on the three main processes regulating the composition of the proteome: transcription, translation, and protein degradation. The reported differences between eLTM and ILTM formation might be due to a different regulation of these processes.

\section{Cyclic AMP-, $\mathrm{Ca}^{2+}$-, and $\mathrm{IP}_{3}$-dependent processes play a role in eLTM and ILTM formation}

Candidate mechanisms for regulating transcription, translation, and protein degradation in honeybees are the signaling cascades involved in the formation of eLTM and ILTM.

Protein kinase A (PKA) plays a central role in eLTM and ILTM formation, as has been shown through experiments that systematically interfere with PKA activity and antisense oligonucleotide inhibition of a PKA regulatory subunit in the honeybee brain (Fiala et al. 1999; Müller 2000). The AL is the the first-order olfactory neuropile of the honeybee brain receiving direct input from olfactory receptors and reward relaying neurons (Sandoz 2011). PKA activity in the AL underlies eLTM and ILTM formation and is regulated by cGMP and cAMP (Müller 2000; Leboulle and Müller 2004). Cyclic GMP is subsequently synthesized by the NO-dependent guanylyl cyclase (GC) during conditioning and shortly thereafter (Müller 1996, 2000). In contrast to processes restricted to the AL, systemic inhibition of adenylyl cyclases (AC) blocks ILTM, whereas eLTM is left intact (Matsumoto et al. 2014). This result suggests that different ACs are involved in the formation of eLTM and ILTM shortly after conditioning, a notion that is supported by the cloning and characterization of different AC genes from the honeybee brain (Wachten et al. 2006; Fuss et al. 2010; Balfanz et al. 2012). So, in addition to PKA, other cAMP target proteins such as cyclic-nucleotide gated ion channels (CGN) and exchange proteins (EPAC), might play a role in eLTM and ILTM formation. In line with this, Matsumoto et al. (2014) 
demonstrate that the pharmacological inhibition of CGNs blocks ILTM, whereas it leaves eLTM intact.

$\mathrm{Ca}^{2+}$ is another second messenger that plays a crucial role in honeybee LTM formation. ILTM formation but not eLTM formation depends on intracellular $\mathrm{Ca}^{2+}, \mathrm{Ca}^{2+}$-binding protein Calmodulin (CaM) and $\mathrm{Ca}^{2+} /$ Calmodulin-dependent kinase (CaM kinase) (Perisse et al. 2009; Matsumoto et al. 2014). Two modes of action that increase intracellular $\mathrm{Ca}^{2+}$ following conditioning are conceivable: First, an influx of extracellular $\mathrm{Ca}^{2+}$ through CGNs, NMDA receptors or voltage-dependent $\mathrm{Ca}^{2+}$ channels (Kloppenburg et al. 1999; Grunewald 2003; Cens et al. 2013); second, a release of intracellular $\mathrm{Ca}^{2+}$ from intracellular stores, such as the endoplasmic reticulum, mediated by the second messenger 1,4,5-trisphosphate $\left(\mathrm{IP}_{3}\right)$ (Kamikouchi et al. 1998; Uno et al. 2013). Both mechanisms might play a role in LTM formation. First, reports have demonstrated that ILTM depends on CGNs (see above) and that an NMDA receptor is involved (Mussig et al. 2010), although RNAi inhibition of a honeybee NMDA receptor subunit blocked eLTM formation but not ILTM (Mussig et al. 2010). This contradiction to the dependency of ILTM formation on $\mathrm{Ca}^{2+}$ (Perisse et al. 2009) remains to be clarified. Second, the activity of protein kinase $\mathrm{C}$, which is activated by diacylglycerol (DAG), increases up to $4 \mathrm{~d}$ after classical conditioning (Grunbaum and Müller 1998). Because DAG and $\mathrm{IP}_{3}$ result from a phospholipase C-dependent cleavage of phosphatidylinositol 4,5-bisphosphate $\left(\mathrm{PIP}_{2}\right)$ (Berridge 2009), a learning-dependent increase of $\mathrm{PKC}$ suggests that $\mathrm{IP}_{3}$ increases after conditioning.

Taken together, these findings suggest that candidate signaling cascades regulating transcription, translation, and protein degradation in the honeybee following classical conditioning are the cAMP-dependent signaling cascade, and $\mathrm{IP}_{3-}$, and $\mathrm{Ca}^{2+}$. dependent processes.

In fact, recent reports in vertebrates have demonstrated an involvement of these three signaling molecules in regulating transcription, translation, and protein degradation by the UPS.

Transcription is initiated when transcription factors bind to their target genes; such a factor is the cAMP-response element binding protein (CREB) (Alberini 2009), which is activated by learning. In vertebrates, CREB-dependent transcription is activated by several kinases, including CaMkinase II and PKA at the kinase inducible domain (KID). Upon phosphorylation CREB binds to the transcriptional apparatus, thereby activating the transcription of target genes (for review, see Alberini 2009). AmCREB, a CREB homolog containing the KID domain and the highly conserved DNA binding and dimerization domain, the basic regionleucin zipper (bZIP), has been isolated from honeybee brain. This suggests that AmCREB is a possible target of learning-dependent alterations of cAMP and $\mathrm{Ca}^{2+}$ (Eisenhardt et al. 2003, 2006).

Learning-dependent translation in vertebrates is regulated by initiation factors and elongation factors (for review, see Gal-BenAri et al. 2012). Phosphorylation of the initiation factor eIF2 $a$ generally inhibits protein synthesis but promotes the synthesis of a few transcripts including ATF-4, a repressor of CREB, and plays a critical role in LTM formation (for review, see Costa-Mattioli et al. 2009; Jiang et al. 2010). Mice with reduced levels of phosphorylated eIF2a show enhanced LTM performance (for review, see Costa-Mattioli et al. 2009). Protein synthesis of a gene encoding the transcriptional regulator CHOP that is translated although eIF2 is increased is regulated through open reading frames (uORFS) in its $5^{\prime}$ untranslated region (5' UTRs) (Palam et al. 2011). This is particularly interesting, because different AmCREB splice variants isolated from the honeybee central brain contain different $5^{\prime}$ UTRs, suggesting a differential regulation of their translation by a similar mechanism (Eisenhardt et al. 2003, 2006). Thus, AmCREB is a potential target gene in the learning-dependent regulation of translation.
A second factor that regulates protein synthesis in vertebrates and is implicated in LTM formation is the elongation factor eEF2. The phosphorylation of eEF2 generally inhibits protein synthesis while at the same time enhancing the translation of a small subset of transcripts (for review, see Taha et al. 2013). eEF2 is phosphorylated and inactivated by elongation factor-2 kinase (eEF2K), whose activity is dependent on $\mathrm{Ca}^{2+}$ and calmodulin (CaM) (Kenney et al. 2014). Moreover, this kinase is phosphorylated by PKA in vitro (Redpath and Proud 1993; Diggle et al. 2001), suggesting that PKA and other $\mathrm{Ca}^{2+}$ - and cAMP-dependent processes might be involved in regulating translational elongation.

$\mathrm{Ca}^{2+}$-dependent processes might be involved in regulating the activity of the proteasome as well. Jarome and Helmstetter (2013) propose a critical involvement of the NMDA and CaMKinase II in a proteasome-dependent mechanism of LTM formation after classical conditioning. They demonstrated a $\mathrm{Ca}^{2+/} \mathrm{CaMki-}$ nase II-dependent regulation of the proteasomes' activity in vertebrates following fear conditioning (Jarome et al. 2013), and there is accumulating evidence that protein degradation by the UPS in neurons is regulated through an NMDA-dependent mechanism (for review, see Jarome and Helmstetter 2013).

Taken together, mounting evidence from studies in vertebrates indicates that cAMP via PKA and $\mathrm{Ca}^{2+}$ and CaM-dependent processes take part in regulating transcription, translation, and protein degradation. This makes it plausible that in honeybees, cAMP- and $\mathrm{Ca}^{2+}$-dependent processes that have been demonstrated to be involved in eLTM and ILTM formation may also play a crucial role in regulating transcription, translation, and protein degradation. However, a learning-induced regulation of transcription, translation, and protein degradation by cAMP- and $\mathrm{Ca}^{2+}$ dependent processes remains to be shown in future studies in honeybees. Its demonstration would provide additional evidence for the convergence of molecular processes underlying honeybee and vertebrate associative learning.

\section{Parameters of classical conditioning regulate the molecular mechanisms underlying LTM formation}

How are the molecular processes underlying long-term memory formation in honeybees induced by learning? In honeybees, two main parameters of learning are crucial: the number of trials performed and the inter-trial interval (ITI). Experiments with foraging honeybees have shown that the stability of reward memories correlates with the number of learning trials: one-trial learning leads to a transient memory that is stable for up to $\sim 1$ $\mathrm{d}$, whereas multiple learning trials lead to strong memories lasting up to $10 \mathrm{~d}$ after learning (Menzel 1968). Comparable with LTM formation in free-flying honeybees LTM strength and stability, in harnessed honeybees depends on the number of conditioning trials: one trial, i.e., one CS-US pairing, leads to a weak memory whereas three conditioning trials lead to a strong memory $1 \mathrm{~d}$ following conditioning (Menzel 1990; Müller 1996). Early LTM (eLTM) formation depends on PKA and NO-synthase and ILTM formation depends on $\mathrm{Ca}^{2+}$ after three-trial conditioning but not after one-trial conditioning (Müller 1996; Perisse et al. 2009). In the AL, PKA activity is prolonged following three-trial conditioning when compared with conditioning with one trial (Müller 2000) and PKC activity is significantly enhanced over several days after three-trial conditioning compared with one-trial conditioning (Grunbaum and Müller 1998). Moreover, the sensitivity of LTM formation to inhibitors of translation, transcription, and protein degradation depends on the number of conditioning trials: strong LTMs formed after three-trial conditioning are sensitive to inhibitors of these three processes whereas weak LTMs formed after one-trial conditioning are not (Friedrich et al. 
2004; Felsenberg et al. 2012). When honeybees are conditioned with three trials, a long-lasting enhancement of histone acetylation is observed, whereas one conditioning trial leads to a transient enhancement of histone acetylation (Merschbaecher et al. 2012). Moreover, three-trial conditioning affects the sensitivity of 1 and $2 \mathrm{~d}$ eLTM to drugs that interfere with histone acetylation. One trial affects the sensitivity of eLTM at $1 \mathrm{~d}$ but not at $2 \mathrm{~d}$ (Merschbaecher et al. 2012).

In most of studies where bees were conditioned with three conditioning trials, an ITI of 2 or 10 min was applied, but the different effects of these two ITIs on learning and LTM formation have not been examined. However, an effect of the ITI on LTM formation has been demonstrated in conditioning with five trials. Conditioning with an ITI of $30 \mathrm{sec}$ and 3 min resulted in a significantly weaker ILTM (4 d LTM) than eLTM (1 d LTM), whereas eLTM and ILTM of similar strength were formed when using an ITI of 1 min and 10 min (Gerber et al. 1998).

Late LTM (ILTM) formation following conditioning with five trials is sensitive to the transcriptional inhibitor actinomycin $\mathrm{D}$, depending on the time point of inhibitor injection (Lefer et al. 2012). Menzel et al. (2001) reported a different sensitivity of LTMs to the transcriptional inhibitor actinomycin D, depending on the ITI between five conditioning trials: Actinomycin D inhibits eLTM and ILTM formation following conditioning with an ITI of $10 \mathrm{~min}$ (spaced training), whereas it blocks ILTM but not eLTM formation after conditioning with an ITI of $30 \mathrm{sec}$ (massed training) (Menzel et al. 2001). These studies demonstrate that the number of trials and the ITI between trials regulate molecular mechanisms of LTM formation in honeybees.

\section{Opposing reward memories influence the behavior of foraging honeybees}

Above it is suggested that classical conditioning resembles the way free-flying bees learn to associate the features of a food source with its reward. Interestingly, when the productivity of a food source declines, honeybees decrease their foraging behavior toward this particular food source and shift to a more efficient one (Menzel 1968; Couvillon and Bitterman 1980, 1984; Greggers and Menzel 1993; Greggers and Mauelshagen 1997). But honeybees will return to food sources previously experienced as being productive for several days (Moore et al. 2011; Wagner et al. 2013). Thus, instead of overwriting their memory of a food scource that is no longer rewarded, honeybees form a memory regarding both currently and previously rewarded food sources. The number of training trials and the reward duration affect the honeybee's decline in foraging behavior toward this nonrewarded food source (Menzel 1968; Couvillon and Bitterman 1980, 1984), indicating an interplay between opposing learning processes: learning about the reward provided by a food source and learning about its failure.

The decline in a bee's behavior toward an unrewarded food source resembles the behavioral phenomenon of extinction after withdrawal of the US in classical conditioning of vertebrates, in which animals learn about the failure of a previously experienced US and form an extinction memory concerning this experience (Pavlov 1927; Myers and Davis 2002).

\section{Molecular mechanisms of long-term extinction memory are regulated by the parameters of classical conditioning}

Extinction is observed in harnessed honeybees when the CS alone is presented multiple times after the animals have been successfully conditioned. Several studies examine the extinction of short- term and long-term memories (Bitterman et al. 1983; Sandoz and Pham-Delegue 2004; Stollhoff et al. 2005; Stollhoff and Eisenhardt 2009; Plath et al. 2012). Three behavioral phenomena-renewal, reinstatement, and spontaneous recovery-demonstrate a time- and context-dependent reappearance of the CR after extinction (Bouton 2002; Myers and Davis 2002). These phenomena have first been described in vertebrates and have been interpreted as an indication that the original, extinguished memory is transiently suppressed, but not erased, following extinction learning (Myers and Davis 2002; Bouton and Moody 2004). Two of these behavioral phenomena, reinstatement and spontaneous recovery, have been described in honeybees, demonstrating a time- and context-dependent reappearance of the CR after extinction. This suggests that in honeybees the original, extinguished memory is also surpressed by the extinction memory but not erased following extinction (Sandoz and Pham-Delegue 2004; Stollhoff et al. 2005; Plath et al. 2012).

Stollhoff et al. (2005) studied extinction of eLTM $1 \mathrm{~d}$ after conditioning in harnessed honeybees. They demonstrated that extinction depends on the number of extinction trials: the more extinction trials are applied, the more extinction can be observed (Stollhoff et al. 2005). After two extinction trials a long-term extinction memory is formed and is behaviorally visible $1 \mathrm{~d}$ after extinction (Stollhoff et al. 2005). The formation of this long-term extinction memory is susceptible to an inhibition of protein synthesis (Stollhoff et al. 2005; Stollhoff and Eisenhardt 2009) and to sleep deprivation (Hussaini et al. 2009). Both a susceptibility to protein synthesis inhibition and sleep deprivation indicate that the formation of a long-term extinction memory undergoes a progressive stabilization of the memory trace, i.e., consolidation.

Stollhoff and Eisenhardt (2009) revealed a direct impact of a parameter of classical conditioning, i.e., US duration, on the molecular mechanism of extinction memory formation: Protein synthesis-dependent long-term extinction memory is only observed when the presentation of the US during classical conditioning exceeds 2 sec (Stollhoff and Eisenhardt 2009).

A second study suggests an interrelation between classical conditioning and extinction memory formation and indicates that this interplay is mediated by underlying molecular mechanisms. Felsenberg et al. (2012) extinguished eLTM after classical conditioning and tested the impact of the UPS inhibitor MG132 on the formation of a long-term extinction memory. They reported an inhibition of long-term extinction memory by MG132. Because an enhancement of LTM formation after classical conditioning by the UPS inhibitor was observed in this study (see above), the authors concluded that extinction $1 \mathrm{~d}$ after classical conditioning results in strengthening the original memory (re)activated upon extinction. This strengthened original memory controls behavior despite the fact that extinction takes place. Accordingly, protein degradation might constrain the original memory following extinction, a mechanism that permits the behavioral expression of extinction memory (Felsenberg et al. 2012). The effect of MG132 on long-term extinction memory formation depends on the number of conditioning trials performed during classical conditioning, indicating that molecular mechanisms such as protein degradation during long-term extinction memory formation crucially depend on the parameters of classical conditioning.

Additionally, a third study on the role of epigenetic mechanisms suggests an interrelation between molecular mechanisms of LTM formation following classical conditioning and extinction: Lockett et al. (2010) demonstrated that the application of a DNA methyltransferase 3 inhibitor $24 \mathrm{~h}$ before and immediately after conditioning enhances extinction of a $1 \mathrm{~d}$ LTM. This suggests that methylation before and during conditioning prevents rapid extinction $24 \mathrm{~h}$ later and accordingly increases the 
LTM's resistance to extinction. In contrast, application of the same inhibitor $2 \mathrm{~h}$ before extinction inhibits it, suggesting that methylation $22 \mathrm{~h}$ after acquisition enhances extinction (Lockett et al. 2010). Thus, gene methylation during conditioning might be the prerequisite for the formation of a stable memory, counteracting the control of behavior by extinction memories. Methylation at later time points after conditioning might lower the resistance to extinction. These findings suggest that DNA methylation has an impact on the balance between the original memory and the extinction memory.

How can these results be reconciled? Two studies reviewed above show that the parameters of learning have an impact on LTM strength and its underlying molecular mechanisms in honeybees. According to Rescorla and Wagner (1972), the cause for extinction and extinction learning is a mismatch between the predicted occurrence of the US following classical conditioning and the experienced failure of the US during extinction. The more conditioning trials an animal experienced, the more association strength, i.e., predictive power, the CS acquired. Thus, the extent of a mismatch between what is predicted by the CS and what is experienced is smaller when animals have been conditioned with a short US than with a long US (see Stollhoff et al. 2009) or when the animals have been conditioned with one trial rather than with many trials (see Felsenberg et al. 2012). Accordingly, both studies suggest that the extent of the mismatch has to exceed a certain threshold to trigger molecular mechanisms of long-term extinction memory formation. These mechanisms might ensure that LTMs are formed only when meaningful changes in US magnitude (i.e., its duration) or US reliability (i.e., the number of trials during conditioning) occur. Such findings suggest that during learning, long-lasting memories are compared with current experiences and that the outcome of this comparison is crucial for the molecular mechanisms of LTM formation. Because studies on extinction in honeybees indicate the formation of a parallel extinction memory, the comparison of current experiences with previous memories triggers the formation of a new long-term memory instead of overwriting the initially formed memory. Thus two opposing memories, the initial memory formed and the extinction memory, together contribute to behavior when the animals encounter the respective stimuli and most likely enable honeybees, depending on the weight of each memory, to return to food sources previously experienced as being productive for several days (Moore et al. 2011; Wagner et al. 2013).

\section{Conclusion}

As described above, the honeybee is one of the best characterized invertebrate organisms with regards to classical conditioning phenomena. Our studies on the molecular mechanisms of long-term memory formation in honeybees indicate that the parameters of classical conditioning induce long-term memory formation following classical conditioning and extinction. These findings suggest that in honeybees, LTM formation depends on a bee's previous experiences in addition to its current learning experience. Moreover, these studies demonstrate how an in-depth analysis of the molecular mechanisms of learning behavior can add to our understanding of associative learning in honeybees. Therefore, future studies on the molecular mechanisms underlying phenomena related to classical conditioning in honeybees, such as backward conditioning (Felsenberg et al. 2014a) or trace conditioning (Szyszka et al. 2011) will lead to a greater understanding of the connection between molecular and behavioral processes.

The honeybee genome was sequenced in 2006 (Honeybee Genome Sequencing Consortium 2006), and assembly and annotation of the genome have been upgraded in 2014. This has im- proved our insights into genomic structure through an improved gene set and a more comprehensive knowledge of protein functions (Elsik et al. 2014). This growing wealth of information is crucial for an efficient analysis of the molecular mechanisms underlying learning and memory in honeybees. It permits a comparision of genes and proteins involved in associative learning in honeybees and vertebrates, the development of tools for the analysis of molecular processes, including antibodies, predictions about the effects of existing pharmacological agents in honeybee behavioral pharmacology, and choosing appropriate oligonucleotide or RNAi sequences to interfere with gene functions during learning and memory formation (Fiala et al. 1999; Mussig et al. 2010; El Hassani et al. 2012; Leboulle et al. 2013). Moreover, information about gene sequences and the potential functions of the proteins they encode, combined with emerging techniques aimed at generating transgenic bees (Schulte et al. 2014), will further the molecular analysis of honeybee learning and memory formation. Thus this molecular information on the honeybee, combined with existing knowledge on the molecular mechanisms that underlie honeybee memory formation and the high convergence of classical conditioning phenomena in honeybees and vertebrates, will advance future in-depth analysis of the mechanisms of honeybee classical conditioning and should equally contribute to our understanding of associative learning in vertebrates.

\section{Acknowledgments}

Funding for this research was provided by Deutsche Forschungsgemeinschaft (FOR1363) and the German Federal Ministry of Education and Research (BMBF) (01GQ0941).

\section{References}

Alberini CM. 2008. The role of protein synthesis during the labile phases of memory: revisiting the skepticism. Neurobiol Learn Mem 89: 234-246.

Alberini CM. 2009. Transcription factors in long-term memory and synaptic plasticity. Physiol Rev 89: 121-145.

Avargues-Weber A, Giurfa M. 2013. Conceptual learning by miniature brains. Proc Biol Sci 280: 20131907.

Balfanz S, Ehling P, Wachten S, Jordan N, Erber J, Mujagic S, Baumann A. 2012. Functional characterization of transmembrane adenylyl cyclases from the honeybee brain. Insect Biochem Mol Biol 42: 435-445.

Bargmann CI, Marder E. 2013. From the connectome to brain function. Nat Methods 10: $483-490$.

Berridge MJ. 2009. Inositol trisphosphate and calcium signalling mechanisms. Biochim Biophys Acta 1793: 933-940.

Biergans SD, Jones JC, Treiber N, Galizia CG, Szyszka P. 2012. DNA methylation mediates the discriminatory power of associative long-term memory in honeybees. PLoS One 7: e39349.

Bitterman ME, Menzel R, Fietz A, Schafer S. 1983. Classical-conditioning of proboscis extension in honeybees (Apis Mellifera). J Comp Psychol 97: 107-119.

Boersma D, McGill S, Mollenkamp J, Roufa DJ. 1979. Emetine resistance in Chinese hamster cells. Analysis of ribosomal proteins prepared from mutant cells. J Biol Chem 254: 559-567.

Bouton ME. 1993. Context, time, and memory retrieval in the interference paradigms of Pavlovian learning. Psychol Bull 114: 80-99.

Bouton ME. 2002. Context, ambiguity, and unlearning: sources of relapse after behavioral extinction. Biol Psychiatry 52: 976-986.

Bouton ME, Moody EW. 2004. Memory processes in classical conditioning. Neurosci Biobehav Rev 28: 663-674.

Buchanan GM, Bitterman ME. 1988. Learning in honeybees as a function of amount and frequency of reward. Anim Learn Behav 16: 247-255.

Buchanan GM, Bitterman ME. 1989. Learning in honeybees as a function of amount of reward-tests of the equal-asymptote assumption. Anim Learn Behav 17: 475-480.

Cens T, Rousset M, Collet C, Raymond V, Demares F, Quintavalle A, Bellis M, Le Conte Y, Chahine M, Charnet P. 2013. Characterization of the first honeybee $\mathrm{Ca}^{2+}$ channel subunit reveals two novel species- and splicing-specific modes of regulation of channel inactivation. Pflugers Arch 465: $985-996$.

Chandra SB, Wright GA, Smith BH. 2010. Latent inhibition in the honey bee, Apis mellifera: is it a unitary phenomenon? Anim Cogn 13: $805-815$. 
Cho Y, Cavalli V. 2014. HDAC signaling in neuronal development and axon regeneration. Curr Opin Neurobiol 27C: 118-126.

Costa-Mattioli M, Sossin WS, Klann E, Sonenberg N. 2009. Translational control of long-lasting synaptic plasticity and memory. Neuron 61: $10-26$

Couvillon PA, Bitterman ME. 1980. Some phenomena of associative learning in honeybees. J Comp Physiol Psychol 94: 578-885.

Couvillon PA, Bitterman ME. 1984. The overlearning-extinction effect and successive negative contrast in honeybees (Apis mellifera). J Comp Psychol 98: 100-109.

Couvillon PA, Bitterman ME. 1993. Learning in honeybees as a function of amount of reward-further experiments with color. Anim Learn Behav 21: $23-28$.

Couvillon PA, Lee YL, Bitterman ME. 1991. Learning in honeybees as a function of amount of reward-rejection of the equal-asymptote assumption. Anim Learn Behav 19: 381-387.

Couvillon P, Nagrampa JA, Bitterman M. 1994. Learning in honeybees (Apis mellifera) as a function of sucrose concentration: analysis of the retrospective effect. J Comp Psychol 108: 274.

Dacher M, Smith BH. 2008. Olfactory interference during inhibitory backward pairing in honey bees. PLoS One 3: e3513.

Denniston JC, Miller RR. 2007. Timing of omitted events: an analysis of temporal control of inhibitory behavior. Behav Processes 74: 274-285

Diggle TA, Subkhankulova T, Lilley KS, Shikotra N, Willis AE, Redpath NT. 2001. Phosphorylation of elongation factor-2 kinase on serine 499 by cAMP-dependent protein kinase induces $\mathrm{Ca}^{2+} /$ calmodulinindependent activity. Biochem J 353: 621-626.

Dudai Y. 2004. The neurobiology of consolidations, or, how stable is the engram? Annu Rev Psychol 55: 51-86.

Edge AA, van Nest BN, Johnson JN, Miller SN, Naeger N, Boyd SD, Moore D. 2012. Diel nectar secretion rhythm in squash (Cucurbita pepo) and its relation with pollinator activity. Apidologie 43: 1-16.

Eisenhardt D. 2006. Learning and memory formation in the honeybee (Apis mellifera) and its dependency on the cAMP-protein kinase A pathway. Anim Biol 56: 259-278.

Eisenhardt D, Menzel R. 2007. Extinction learning, reconsolidation and the internal reinforcement hypothesis. Neurobiol Learn Mem 87: 167-173.

Eisenhardt D, Friedrich A, Stollhoff N, Müller U, Kress H, Menzel R. 2003. The AmCREB gene is an ortholog of the mammalian CREB/CREM family of transcription factors and encodes several splice variants in the honeybee brain. Insect Mol Biol 12: 373-382.

Eisenhardt D, Kuhn C, Leboulle G. 2006. The PKA-CREB system encoded by the honeybee genome. Insect Mol Biol 15: 551-561.

El Hassani AK, Schuster S, Dyck Y, Demares F, Leboulle G, Armengaud C. 2012. Identification, localization and function of glutamate-gated chloride channel receptors in the honeybee brain. Eur J Neurosci 36: 2409-2420.

Elsik CG, Worley KC, Bennett AK, Beye M, Camara F, Childers CP, de Graaf DC, Debyser G, Deng J, Devreese B, et al. 2014. Finding the missing honey bee genes: lessons learned from a genome upgrade. BMC Genomics 15: 86

Fanselow MS. 1998. Pavlovian conditioning, negative feedback, and blocking: mechanisms that regulate association formation. Neuron 20: $625-627$.

Felsenberg J, Gehring KB, Antemann V, Eisenhardt D. 2011. Behavioural pharmacology in classical conditioning of the proboscis extension response in honeybees (Apis mellifera). J Vis Exp. doi: 10.3791/2282.

Felsenberg J, Dombrowski V, Eisenhardt D. 2012. A role of protein degradation in memory consolidation after initial learning and extinction learning in the honeybee (Apis mellifera). Learn Mem 19: $470-477$.

Felsenberg J, Plath JA, Lorang S, Morgenstern L, Eisenhardt D. 2014a. Shortand long-term memories formed upon backward conditioning in honeybees (Apis mellifera). Learn Mem 21: 37-45.

Felsenberg J, Dyck Y, Kloss A, Dahlmann B, Klotzel PM, Eisenhardt D. 2014b. Two inhibitors of the ubiquitin proteasome system enhance long-term memory formation upon olfactory conditioning in the honeybee (Apis Mellifera). J Exp Biol doi: 0.1242/jeb.108142.

Fiala A, Müller U, Menzel R. 1999. Reversible downregulation of protein kinase A during olfactory learning using antisense technique impairs long-term memory formation in the honeybee, Apis mellifera. J Neurosci 19: $10125-10134$.

Free J. 1963. The flower constancy of honeybees. J Anim Ecol 32: 119-131.

Friedrich A, Thomas U, Müller U. 2004. Learning at different satiation levels reveals parallel functions for the cAMP-protein kinase A cascade in formation of long-term memory. J Neurosci 24: 4460-4468.

Fuss N, Mujagic S, Erber J, Wachten S, Baumann A. 2010. Biochemical properties of heterologously expressed and native adenylyl cyclases from the honeybee brain (Apis mellifera L.). Insect Biochem Mol Biol 40: $573-580$.

Gal-Ben-Ari S, Kenney JW, Ounalla-Saad H, Taha E, David O, Levitan D, Gildish I, Panja D, Pai B, Wibrand K, et al. 2012. Consolidation and translation regulation. Learn Mem 19: 410-422.
Gerber B, Ullrich J. 1999. No evidence for olfactory blocking in honeybee classical conditioning. J Exp Biol 202(Pt 13): 1839-1854.

Gerber B, Wustenberg D, Schutz A, Menzel R. 1998. Temporal determinants of olfactory long-term retention in honeybee classical conditioning: nonmonotonous effects of the training trial interval. Neurobiol Learn Mem 69: 71-78.

Gewirtz JC, Davis M. 2006. Using Pavlovian higher order conditioning paradigms to investigate the neural substrates of emotional learning and memory. Learn Mem 7: 257-266.

Gil M. 2010. Reward expectations in honeybees. Commun Integr Biol 3: 95-100.

Gil M, De Marco RJ. 2009. Honeybees learn the sign and magnitude of reward variations. J Exp Biol 212: 2830-2834.

Gil M, De Marco RJ, Menzel R. 2007. Learning reward expectations in honeybees. Learn Mem 14: 491-496.

Giurfa M, Sandoz JC. 2012. Invertebrate learning and memory: fifty years of olfactory conditioning of the proboscis extension response in honeybees. Learn Mem 19: 54-66.

Glanzman DL. 2010. Common mechanisms of synaptic plasticity in vertebrates and invertebrates. Curr Biol 20: R31-R36.

Greggers U, Mauelshagen J. 1997. Matching behavior of honeybees in a multiple-choice situation: the differential effect of environmental stimuli on the choice process. Anim Learn Behav 25: $458-472$.

Greggers U, Menzel R. 1993. Memory dynamics and foraging strategies of honeybees. Behav Ecol Sociobiol 32: 17-29.

Grollman AP. 1968. Inhibitors of protein biosynthesis. V. Effects of emetine on protein and nucleic acid biosynthesis in HeLa cells. J Biol Chem 243: 4089-4094.

Grunbaum L, Müller U. 1998. Induction of a specific olfactory memory leads to a long-lasting activation of protein kinase $\mathrm{C}$ in the antennal lobe of the honeybee. J Neurosci 18: 4384-4392.

Grunewald B. 2003. Differential expression of voltage-sensitive $\mathrm{K}^{+}$and $\mathrm{Ca}^{2+}$ currents in neurons of the honeybee olfactory pathway. J Exp Biol 206: $117-129$.

Gruter C, Moore H, Firmin N, Helantera H, Ratnieks FL. 2011. Flower constancy in honey bee workers (Apis mellifera) depends on ecologically realistic rewards. J Exp Biol 214: 1397-1402.

Guerrieri F, Lachnit H, Gerber B, Giurfa M. 2005. Olfactory blocking and odorant similarity in the honeybee. Learn Mem 12: 86-95.

Gupta RS, Siminovitch L. 1977. The molecular basis of emetine resistance in Chinese hamster ovary cells: alteration in the $40 \mathrm{~S}$ ribosomal subunit. Cell 10: 61-66.

Hammer M, Menzel R. 1995. Learning and memory in the honeybee. J Neurosci 15: 1617-1630.

Hansen JL, Moore PB, Steitz TA. 2003. Structures of five antibiotics bound at the peptidyl transferase center of the large ribosomal subunit. J Mol Biol 330: $1061-1075$

Hellstern F, Malaka R, Hammer M. 1998. Backward inhibitory learning in honeybees: a behavioral analysis of reinforcement processing. Learn Mem 4: $429-444$

Hempel de Ibarra N, Vorobyev M, Menzel R. 2014. Mechanisms, functions and ecology of colour vision in the honeybee. J Comp Physiol A Neuroethol Sens Neural Behav Physiol 200: 411-433.

Hoban JS, Couvillon PA, Bitterman ME. 1996. Odor preference in honeybees as a function of amount of reward: tests of two explanations. J Insect Behav 9: 121-132.

Honeybee Genome Sequencing Consortium. 2006. Insights into social insects from the genome of the honeybee Apis mellifera. Nature 443: 931-949.

Hourcade B, Perisse E, Devaud JM, Sandoz JC. 2009. Long-term memory shapes the primary olfactory center of an insect brain. Learn Mem 16: 607-615.

Hourcade B, Muenz TS, Sandoz JC, Rossler W, Devaud JM. 2010. Long-term memory leads to synaptic reorganization in the mushroom bodies: a memory trace in the insect brain? J Neurosci 30: 6461-6465.

Hussaini SA, Komischke B, Menzel R, Lachnit H. 2007. Forward and backward second-order Pavlovian conditioning in honeybees. Learn Mem 14: 678-683.

Hussaini SA, Bogusch L, Landgraf T, Menzel R. 2009. Sleep deprivation affects extinction but not acquisition memory in honeybees. Learn Mem 16: 698-705.

Jarome TJ, Helmstetter FJ. 2013. The ubiquitin-proteasome system as a critical regulator of synaptic plasticity and long-term memory formation. Neurobiol Learn Mem 105: 107-116.

Jarome TJ, Kwapis JL, Ruenzel WL, Helmstetter FJ. 2013. CaMKII, but not protein kinase A, regulates Rpt6 phosphorylation and proteasome activity during the formation of long-term memories. Front Behav Neurosci 7: 115

Jiang Z, Belforte JE, Lu Y, Yabe Y, Pickel J, Smith CB, Je HS, Lu B, Nakazawa K. 2010. eIF2 $\alpha$ Phosphorylation-dependent translation in CA1 pyramidal 
cells impairs hippocampal memory consolidation without affecting general translation. J Neurosci 30: 2582-2594.

Kahne T, Kolodziej A, Smalla KH, Eisenschmidt E, Haus UU, Weismantel R, Kropf S, Wetzel W, Ohl FW, Tischmeyer W, et al. 2012. Synaptic proteome changes in mouse brain regions upon auditory discrimination learning. Proteomics 12: 2433-2444.

Kamikouchi A, Takeuchi H, Sawata M, Ohashi K, Natori S, Kubo T. 1998. Preferential expression of the gene for a putative inositol 1,4,5trisphosphate receptor homologue in the mushroom bodies of the brain of the worker honeybee Apis mellifera L. Biochem Biophys Res Commun 242: 181-186.

Kenney JW, Moore CE, Wang X, Proud CG. 2014. Eukaryotic elongation factor 2 kinase, an unusual enzyme with multiple roles. Adv Biol Regul 55: $15-27$.

Kloppenburg P, Kirchhof BS, Mercer AR. 1999. Voltage-activated currents from adult honeybee (Apis mellifera) antennal motor neurons recorded in vitro and in situ. J Neurophysiol 81: 39-48.

Leboulle G, Müller U. 2004. Synergistic activation of insect cAMPdependent protein kinase A (type II) by cyclicAMP and cyclicGMP. FEBS Lett 576: 216-220.

Leboulle G, Niggebrugge C, Roessler R, Briscoe AD, Menzel R, Hempel de Ibarra N. 2013. Characterisation of the RNA interference response against the long-wavelength receptor of the honeybee. Insect Biochem Mol Biol 43: 959-969.

Lee YL, Bitterman ME. 1990. Learning in honeybees (Apis Mellifera) as a function of amount of reward-acquisition measures. J Comp Psychol 104: $152-158$.

Lefer D, Perisse E, Hourcade B, Sandoz J, Devaud JM. 2012. Two waves of transcription are required for long-term memory in the honeybee. Learn Mem 20: 29-33.

Li-Byarlay H, Li Y, Stroud H, Feng S, Newman TC, Kaneda M, Hou KK, Worley KC, Elsik CG, Wickline SA, et al. 2013. RNA interference knockdown of DNA methyl-transferase 3 affects gene alternative splicing in the honey bee. Proc Natl Acad Sci 110: 12750-12755.

Lockett GA, Helliwell P, Maleszka R. 2010. Involvement of DNA methylation in memory processing in the honey bee. Neuroreport 21: 812-816.

Loo SK, Bitterman M. 1992. Learning in honeybees (Apis mellifera) as a function of sucrose concentration. J Comp Psychol 106: 29.

Matsumoto Y, Menzel R, Sandoz JC, Giurfa M. 2012. Revisiting olfactory classical conditioning of the proboscis extension response in honey bees: a step toward standardized procedures. J Neurosci Methods 211: $159-167$

Matsumoto Y, Sandoz JC, Devaud JM, Lormant F, Mizunami M, Giurfa M. 2014. Cyclic nucleotide-gated channels, calmodulin, adenylyl cyclase, and calcium/calmodulin-dependent protein kinase II are required for late, but not early, long-term memory formation in the honeybee. Learn Mem 21: 272-286.

Menzel R. 1968. On honey bees memory of spectral colours. I. Long-term and short-term retention. Z Vgl Physiol 60: 82-102.

Menzel R. 1990. Learning, memory, and "cognition" in honey bees. In Neurobiology of Comparative Cognition (ed. Kesner RP, Olton DS), pp. 237-292. Lawrence Erlbaum Associate, Hillsdale, NJ.

Menzel R. 1999. Memory dynamics in the honeybee. J Comp Physiol A Neuroethol Sens Neural Behav Physiol 185: 323-340.

Menzel R. 2001. Searching for the memory trace in a mini-brain, the honeybee. Learn Mem 8: 53-62.

Menzel R. 2012. The honeybee as a model for understanding the basis of cognition. Nat Rev Neurosci 13: 758-768.

Menzel R, Erber J. 1972. The Influence of the Quantity of Reward on Learning Performance in Honeybees. Behaviour 41: 27-42.

Menzel R, Manz G, Greggers U. 2001. Massed and spaced learning in honeybees: the role of CS, US, the intertrial interval, and the test interval. Learn Mem 8: 198-208.

Merschbaecher K, Haettig J, Mueller U. 2012. Acetylation-mediated suppression of transcription-independent memory: bidirectional modulation of memory by acetylation. PLoS One 7: e45131.

Moore D. 2001. Honey bee circadian clocks: behavioral control from individual workers to whole-colony rhythms. J Insect Physiol 47: 843-857.

Moore D, Doherty P. 2009. Acquisition of a time-memory in forager honey bees. J Comp Physiol A Neuroethol Sens Neural Behav Physiol 195: $741-751$.

Moore D, Van Nest BN, Seier E. 2011. Diminishing returns: the influence of experience and environment on time-memory extinction in honey bee foragers. J Comp Physiol A Neuroethol Sens Neural Behav Physiol 197: 641-651.

Mota T, Giurfa M, Sandoz JC. 2011. Color modulates olfactory learning in honeybees by an occasion-setting mechanism. Learn Mem 18: 144-155

Müller U. 1996. Inhibition of nitric oxide synthase impairs a distinct form of long-term memory in the honeybee, Apis mellifera. Neuron 16: $541-549$.
Müller U. 2000. Prolonged activation of cAMP-dependent protein kinase during conditioning induces long-term memory in honeybees. Neuron 27: $159-168$.

Müller U. 2002. Learning in honeybees: from molecules to behaviour. Zoology (Jena) 105: 313-320.

Müller U. 2013. Memory phases and signaling cascades in honeybees. In Invertebrate learning and memory (ed. Benjamin PR, Menzel R), pp. 433-441. Elsevier, London.

Müller D, Gerber B, Hellstern F, Hammer M, Menzel R. 2000. Sensory preconditioning in honeybees. J Exp Biol 203: 1351-1364.

Mussig L, Richlitzki A, Rossler R, Eisenhardt D, Menzel R, Leboulle G. 2010. Acute disruption of the NMDA receptor subunit NR1 in the honeybee brain selectively impairs memory formation. J Neurosci 30: $7817-7825$.

Myers KM, Davis M. 2002. Behavioral and neural analysis of extinction. Neuron 36: $567-584$.

Nithianantharajah J, Komiyama NH, McKechanie A, Johnstone M, Blackwood DH, St Clair D, Emes RD, van de Lagemaat LN, Saksida LM, Bussey TJ, et al. 2013. Synaptic scaffold evolution generated components of vertebrate cognitive complexity. Nat Neurosci 16: $16-24$.

Palam LR, Baird TD, Wek RC. 2011. Phosphorylation of eIF2 facilitates ribosomal bypass of an inhibitory upstream ORF to enhance CHOP translation. J Biol Chem 286: 10939-10949.

Pamir E, Chakroborty NK, Stollhoff N, Gehring KB, Antemann V, Morgenstern L, Felsenberg J, Eisenhardt D, Menzel R, Nawrot MP. 2011. Average group behavior does not represent individual behavior in classical conditioning of the honeybee. Learn Mem 18: $733-741$

Paramanathan T, Vladescu I, McCauley MJ, Rouzina I, Williams MC. 2012. Force spectroscopy reveals the DNA structural dynamics that govern the slow binding of Actinomycin D. Nucleic Acids Res 40: $4925-4932$.

Pavlov IP. 1927. Conditioned reflexes: an investigation of the physiological activity of the cerebral cortex. Oxford University Press.

Perisse E, Raymond-Delpech V, Neant I, Matsumoto Y, Leclerc C, Moreau M, Sandoz JC. 2009. Early calcium increase triggers the formation of olfactory long-term memory in honeybees. BMC Biol 7: 30 .

Plath JA, Felsenberg J, Eisenhardt D. 2012. Reinstatement in honeybees is context-dependent. Learn Mem 19: 543-549.

Puckett RE, Lubin FD. 2011. Epigenetic mechanisms in experience-driven memory formation and behavior. Epigenomics 3: 649-664.

Radulovic J, Tronson NC. 2008. Protein synthesis inhibitors, gene superinduction and memory: too little or too much protein? Neurobiol Learn Mem 89: 212-218.

Raybuck JD, Lattal KM. 2014. Bridging the interval: theory and neurobiology of trace conditioning. Behav Processes 101: 103-111.

Redpath NT, Proud CG. 1993. Cyclic AMP-dependent protein kinase phosphorylates rabbit reticulocyte elongation factor- 2 kinase and induces calcium-independent activity. Biochem J 293(Pt 1): 31-34.

Rescorla RA, Wagner AR. 1972. A theory of Pavlovian conditioning: variations in the effectiveness of reinforcement and nonreinforcement. In Classical conditioning II current theory and research (ed. Black AH, Prokasy WF), pp. 64-99. Appleton-Century-Crofts, New York.

Rhoads DD, Roufa DJ. 1985. Emetine resistance of Chinese hamster cells: structures of wild-type and mutant ribosomal protein S14 mRNAs. Mol Cell Biol 5: 1655-1659.

Ryan TJ, Kopanitsa MV, Indersmitten T, Nithianantharajah J, Afinowi NO, Pettit C, Stanford LE, Sprengel R, Saksida LM, Bussey TJ, et al. 2013. Evolution of GluN2A/B cytoplasmic domains diversified vertebrate synaptic plasticity and behavior. Nat Neurosci 16: $25-32$.

Sandoz JC. 2011. Behavioral and neurophysiological study of olfactory perception and learning in honeybees. Front Syst Neurosci 5: 98.

Sandoz JC, Pham-Delegue MH. 2004. Spontaneous recovery after extinction of the conditioned proboscis extension response in the honeybee. Learn Mem 11: 586-597.

Schmajuk NA, Lamoureux JA, Holland PC. 1998. Occasion setting: a neural network approach. Psychol Rev 105: 3-32.

Schulte C, Theilenberg E, Müller-Borg M, Gempe T, Beye M. 2014. Highly efficient integration and expression of piggyBac-derived cassettes in the honeybee (Apis mellifera). Proc Natl Acad Sci 111: 2003-2008.

Schwärzel M, Müller U. 2006. Dynamic memory networks: dissecting molecular mechanisms underlying associative memory in the temporal domain. Cell Mol Life Sci 63: 989-998.

Seeley TD. 1995. The wisdom of the hive: the social physiology of honey bee colonies. Harvard University Press, Cambridge, MA.

Seeley TD, Visscher P. 1985. Survival of honeybees in cold climates: the critical timing of colony growth and reproduction. Ecol Entomol 10: $81-88$.

Sobell HM. 1985. Actinomycin and DNA transcription. Proc Natl Acad Sci 82: $5328-5331$. 
Sommer T, Wolf DH. 2014. The ubiquitin-proteasome-system. Biochim Biophys Acta 1843: 1.

Stollhoff N, Eisenhardt D. 2009. Consolidation of an extinction memory depends on the unconditioned stimulus magnitude previously experienced during training. J Neurosci 29: 9644-9650.

Stollhoff N, Menzel R, Eisenhardt D. 2005. Spontaneous recovery from extinction depends on the reconsolidation of the acquisition memory in an appetitive learning paradigm in the honeybee (Apis mellifera). J Neurosci 25: 4485-4492.

Szyszka P, Demmler C, Oemisch M, Sommer L, Biergans S, Birnbach B, Silbering AF, Galizia CG. 2011. Mind the gap: olfactory trace conditioning in honeybees. J Neurosci 31: 7229-7239.

Taha E, Gildish I, Gal-Ben-Ari S, Rosenblum K. 2013. The role of eEF2 pathway in learning and synaptic plasticity. Neurobiol Learn Mem 105: 100-106.

Takeda K. 1961. Classical Conditioned Response in the Honey Bee. J Insect Physiol 6: 168-179.

Uno Y, Fujiyuki T, Morioka M, Kubo T. 2013. Mushroom body-preferential expression of proteins/genes involved in endoplasmic reticulum $\mathrm{Ca}(2+)$-transport in the worker honeybee (Apis mellifera L.) brain. Insect Mol Biol 22: 52-61. von Frisch K. 1967. The dance language and orientation of bees. Belknap Press of Harvard University Press.

Wachten S, Schlenstedt J, Gauss R, Baumann A. 2006. Molecular identification and functional characterization of an adenylyl cyclase from the honeybee. J Neurochem 96: 1580-1590.

Wagner AE, Van Nest BN, Hobbs CN, Moore D. 2013. Persistence, reticence and the management of multiple time memories by forager honey bees. J Exp Biol 216: 1131-1141.

Winston ML. 1991. The biology of the honey bee. Harvard University Press.

Wong W, Bai XC, Brown A, Fernandez IS, Hanssen E, Condron M, Tan YH, Baum J, Scheres SH. 2014. Cryo-EM structure of the Plasmodium falciparum $80 \mathrm{~S}$ ribosome bound to the anti-protozoan drug emetine. eLife e03080.

Wustenberg D, Gerber B, Menzel R. 1998. Short communication: long- but not medium-term retention of olfactory memories in honeybees is impaired by actinomycin D and anisomycin. Eur J Neurosci 10: $2742-2745$

Received June 8, 2014; accepted in revised form July 28, 2014. 
Learning \& Memory 21: 478-487 (2014)

Protein degradation by ubiquitin-proteasome system in formation and labilization of contextual conditioning memory

María Sol Fustiñana, Verónica de la Fuente, Noel Federman, Ramiro Freudenthal, and Arturo Romano

In the original version of this article, Verónica de la Fuente was accidentally removed from the list of authors during the composition process. The publisher apologizes for this omission, which has been corrected in the current version online.

Learning \& Memory 21: 534-542 (2014)

Molecular mechanisms underlying formation of long-term reward memories and extinction memories in the honeybee (Apis mellifera)

Dorothea Eisenhardt

The last sentence at the bottom of page 535, column 1, should read: "The honeybee genome project revealed a plethora of honeybee proteins homologous to vertebrate neuronal proteins (Honeybee Genome Sequencing Consortium 2006)." The publisher apologizes for the erroneous typo, which has been corrected in the current version online. 


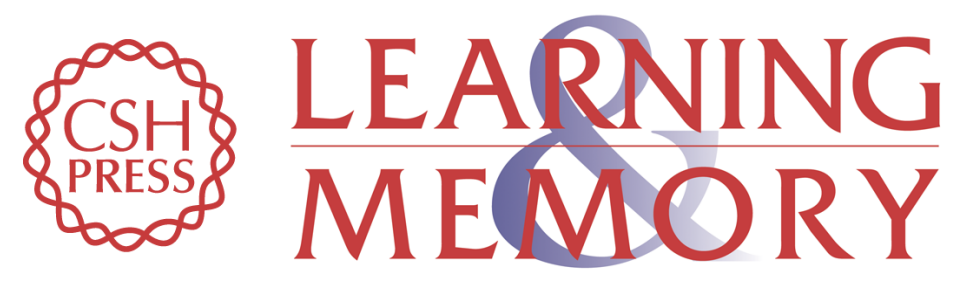

\section{Molecular mechanisms underlying formation of long-term reward memories and extinction memories in the honeybee ( Apis mellifera )}

Dorothea Eisenhardt

Learn. Mem. 2014, 21:

Access the most recent version at doi:10.1101/lm.033118.113
Related Content Molecular mechanisms underlying formation of long-term reward memories and extinction memories in the honeybee (Apis mellifera)
Dorothea Eisenhardt
Learn. Mem. November , 2014 21: 646.2
References This article cites 132 articles, 39 of which can be accessed free at: http://learnmem.cshlp.org/content/21/10/534.full.html\#ref-list-1
Articles cited in:
http://learnmem.cshlp.org/content/21/10/534.full.html\#related-urls
Creative This article is distributed exclusively by Cold Spring Harbor Laboratory Press for the Commons first 12 months after the full-issue publication date (see
License http://learnmem.cshlp.org/site/misc/terms.xhtml). After 12 months, it is available under a Creative Commons License (Attribution-NonCommercial 4.0 International), as described at http://creativecommons.org/licenses/by-nc/4.0/.
Email Alerting Receive free email alerts when new articles cite this article - sign up in the box at the Service top right corner of the article or click here.

